\title{
The impact of the new Global Lung Function Initiative $T L C O$ reference values on trial inclusion for patients with idiopathic pulmonary fibrosis
}

To the Editor:

We read the paper by Derom et al. [1] with great interest. This paper describes the nationwide introduction and implementation of the new Global Lung Function Initiative (GLI) reference equations for spirometry and transfer factor of the lung for carbon monoxide (TLCO) in Belgium $[2,3]$. Convinced of the advantages of using these all-age and globally most accurate reference value set available [4], the Belgium Thoracic Society applied a stepwise approach to launching them. The aimed nationwide collective transition is currently ongoing, involving pulmonologists, lung function technologists and equipment manufacturers.

Although one could comment that this approach delayed the implementation of the GLI 2012 spirometry equations in Belgium compared to other countries, we fully endorse the importance of a nationwide implementation based on our findings in a study described below. In daily practice, there are many reference value sets implemented and it is acknowledged that use of different sets may lead to interpretation differences of equal measured TLCO values within an individual patient. For example, this may happen when a patient is referred from one hospital to another. Uniformity in reference sets will not only avoid potential erroneous effects on treatment decisions; it will also provide clarity to patients and investigators for research purposes, especially when looking at eligibility for trial participation. Below, we describe the impact of the new GLI TLCO reference values on trial inclusion for patients with idiopathic pulmonary fibrosis (IPF).

IPF is a progressive and life-threatening interstitial lung disease. Scarring of the lung tissue leads to a restrictive lung function pattern and impaired gas exchange, causing dyspnoea and desaturation on exertion [5]. The TLCO, indicator of the gas exchange function of the lungs, is almost always decreased in patients with IPF $[6,7]$. There is no cure for IPF, except lung transplantation in a select group of patients. Two anti-fibrotic drugs slow disease progression but do not stop or reverse the fibrosis [8]. Multiple clinical trials in IPF are ongoing in search of better treatment. IPF patients are often keen to participate in clinical trials that may give them a chance to improve their disease outcome [9]. Inclusion criteria for these trials usually include a threshold for TLCO \% predicted. Screen failures are frequently based on TLCO below lower limits, and are disappointing to patients. Many lung function laboratories still use older reference values of the European Community for Steel and Coal ("ECSC", 1993) [10], Crapo and Morris (“Crapo", 1981) [11], Miller and co-workers ("Miller", 1983) [12] or Neas and Schwartz (National Health and Nutrition Examination Survey 1971-1975; "NHANES-1", 1996) [13]. Therefore, we assessed the impact of the new GLI TLCO reference equations on trial inclusion for IPF patients.

In a retrospective cohort study, we collected lung function data of consecutive IPF patients, routinely measured in 2017. The TLCO \% predicted was calculated using the older prediction equations and the new GLI (2017) equations. Predicted values were extrapolated if the age of the patient was beyond the data range of the reference population (ECSC, Miller). Only NHANES-1 has different TLCO reference equations for adults with African-American and Caucasian background [13]. We compared the number of patients

@ERSpublications

Adopting the new Global Lung Function Initiative TLCO reference values may positively impact clinical trial eligibility for IPF patients http://ow.ly/bOMn30n2YOP

Cite this article as: Wapenaar M, Miedema JR, Lammering CJ, et al. The impact of the new Global Lung Function Initiative TLCO reference values on trial inclusion for patients with idiopathic pulmonary fibrosis. Eur Respir J 2019; 53: 1801895 [https://doi.org/10.1183/13993003.01895-2018]. 
TABLE 1 Values for transfer factor of the lung for carbon monoxide ( $T L C O$ ), transfer coefficient $(\mathrm{KcO})$ and alveolar volume $\left(\mathrm{VA}_{\mathrm{A}}\right)$ as calculated using the different reference equations

\begin{tabular}{lcccccc} 
& TLco \% pred $^{\#}$ & Z-score & Kco \% pred & Z-score & VA \% pred & Z-score \\
\hline GLI [1] & $37 \%(29-46)$ & -5.0 & $64 \%(52-73)$ & -2.5 & $60 \%(53-69)$ & -3.5 \\
ECSC [10] & $35 \%(28-44)$ & -3.9 & $66 \%(55-78)$ & -1.8 & $55 \%(48-64)$ & -4.1 \\
Crapo [11] & $30 \%(24-38)$ & -4.4 & $55 \%(46-64)$ & -2.5 & $54 \%(47-62)$ & -4.0 \\
Miller [12] & $36 \%(29-45)$ & -3.3 & $65 \%(54-75)$ & -1.9 & $55 \%(48-63)$ & -3.5 \\
NHANES-1" [13] & $33 \%(26-41)$ & & & & &
\end{tabular}

Data are presented as median \% predicted values with interquartile ranges. The Z-score represents the difference between the measured value and the reference population mean in standard deviation units. For example; a Z-score of -3 means that the measured value is far below the 2.5 th percentile in a healthy population. " : TLCO $\%$ predicted values from all older equations were significantly lower than the Global Lung Function Initiative (GLI) TLCo \% predicted ( $p<0.001$, Wilcoxon signed ranks test). ๆ: Z-scores, Kco \% predicted and $V_{A} \%$ predicted could not be calculated. ECSC: European Community for Steel and Coal; NHANES-1: National Health and Nutrition Examination Survey 1971-1975.

eligible for clinical trials that use a threshold of TLCO $\geqslant 30 \%$ predicted. SPSS 24 was used for statistical analysis. The ethics committee of our centre exempted this study from review because of the noninterventional design (MEC-2018-1383).

We included data of 145 patients, 118 (81\%) male, mean \pm SD age $72 \pm 8$ years, 11 (8\%) non-Caucasian. The mean forced vital capacity (FVC) was $75 \pm 16 \%$ predicted, Z-score $-1.6 \pm 1.0$, using GLI 2012 spirometry equations. Calculated with the different equations, the median \% predicted values and Z-scores for the TLCO, the transfer coefficient (KCO) and the alveolar volume $(V A)$ are shown in table 1.

With an inclusion threshold of TLCO $\geqslant 30 \%$ predicted, the number of patients eligible using GLI equations was significantly higher than using the older equations, except for those derived by Miller (McNemar's Test); GLI 104/145 (72\%) patients, ECSC 96/145; (66\%; p=0.008), Crapo 73/145 (50\%; p<0.001), Miller 102/145 (70\%; p=0.69), NHANES-1 81/145 (56\%; p<0.001). Figure 1 shows that for all individual patients, GLI TLCO \% predicted values are consistently higher than TLCO \% predicted values using older equations, except for those of Miller. Using GLI, eligibility status would have changed positively in 2-31 of patients (depending on reference set).

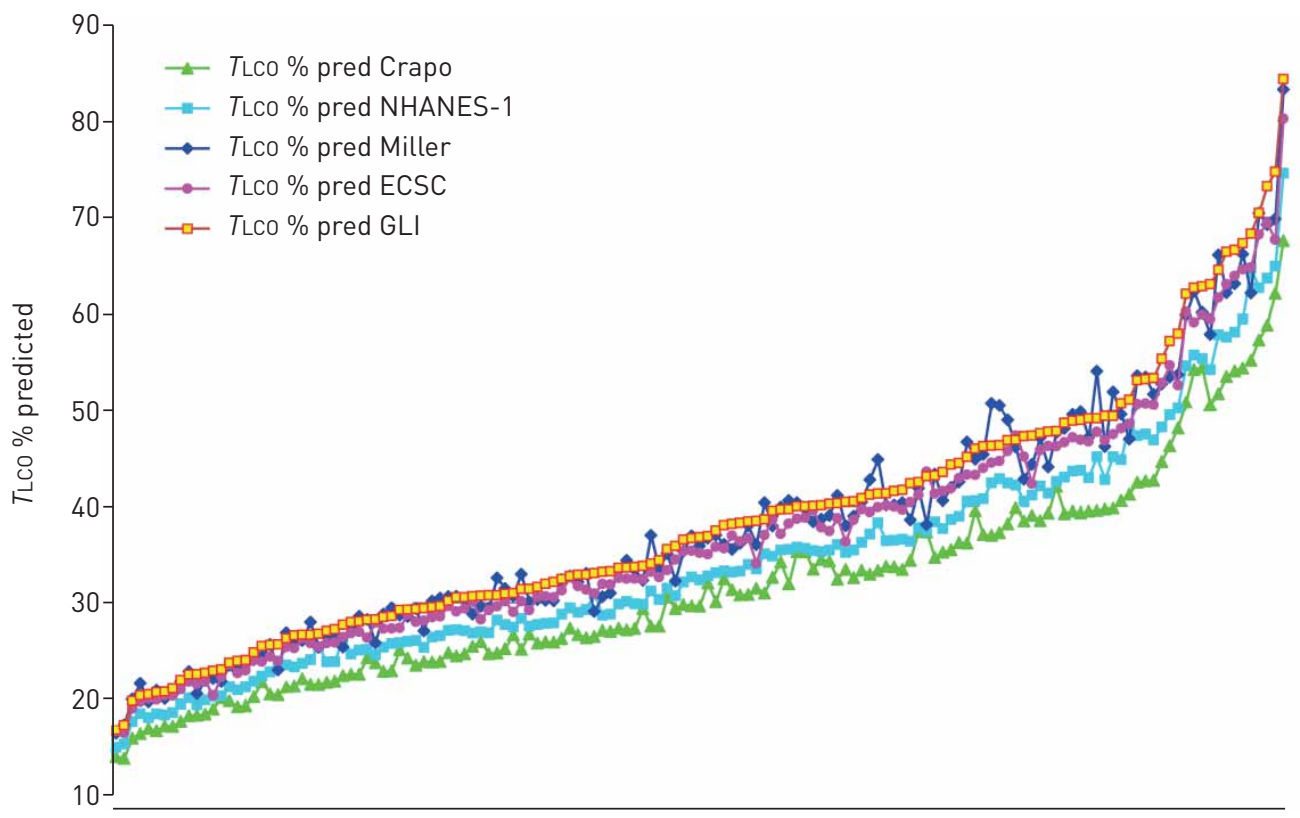

All individual patients $(\mathrm{n}=145)$

FIGURE 1 Transfer factor of the lung for carbon monoxide (TLCO) \% predicted values for all individual patients calculated by the different reference equations. ECSC: European Community for Steel and Coal; NHANES-1: National Health and Nutrition Examination Survey 1971-1975; GLI: Global Lung Function Initiative. 
Our results show that switching to the new GLI TLCO reference equations may have a significant positive effect on trial inclusion for IPF patients. This difference in eligibility may have large implications for the individual patient on clinical trial participation. Not only physicians should be aware of this impact of the choice of reference equations, but also sponsors of clinical trials when writing the study protocol.

Systematic differences between the several predicted values have been explained from differences in sample size, population characteristics and distribution of the ages, equipment and setting, measurement techniques and applied statistical methods $[3,14]$. In our study the Miller TLCO \% predicted values and number of eligible patients were closest to the GLI. This is remarkable considering that $57 \%$ of our patients were $>70$ years of age, outside the age range of Miller's reference population, and reference values were extrapolated. The largest shift in trial eligibility occurred when changing from Crapo to GLI. The higher Crapo predicted values may be explained by physiological adaptations of the reference subjects due to altitude $(1400 \mathrm{~m})$ [12].

Our study shows that urgent adoption of the globally derived and applicable GLI reference set is needed to reduce variability in trial eligibility between laboratories. Currently GLI TLCO equations are only available for Caucasians, which limits their validity. Collecting data to expand the equations are ongoing. However, being derived from the largest dataset ever, measured on modern equipment and representing all ages, this should not prevent adoption of the GLI equations in their current form. The implementation strategy, as described by Derom et al. [1] should hopefully encourage other national societies to follow this path as well, as in the end patients, healthcare providers and researchers will benefit.

Monique Wapenaar ${ }^{1}$, Jelle R. Miedema ${ }^{2}$, Catharina J. Lammering ${ }^{1}$, Frans W. Mertens ${ }^{1}$ and Marlies S. Wijsenbeek ${ }^{2}$ ${ }^{1}$ Pulmonary Function Dept, Erasmus MC, University Medical Center, Rotterdam, The Netherlands. ${ }^{2}$ Dept of Respiratory Medicine, Erasmus MC, University Medical Center, Rotterdam, The Netherlands.

Correspondence: Monique Wapenaar, University Medical Center, Dept of Pulmonary Medicine, Dr. Molewaterplein 40, 3015 GD Rotterdam, Rotterdam, The Netherlands. E-mail: m.wapenaar@erasmusmc.nl

Received: Oct 042018 | Accepted after revision: Nov 202018

Conflict of interest: M. Wapenaar has nothing to disclose. J.R. Miedema has nothing to disclose. C.J. Lammering has nothing to disclose. F.W. Mertens has nothing to disclose. M.S. Wijsenbeek reports institutional fees and grants from Boehringer Ingelheim and Hoffman la Roche, and institutional fees from Galapagos, outside the submitted work.

\section{References}

1 Derom E, Liistro G, Oostveen E, et al. Launching Global Lung Function Initiative reference values in Belgium: tips and tricks. Eur Respir J 2018; 52: 1800922.

2 Quanjer PH, Stanojevic S, Cole TJ, et al. Multi-ethnic reference values for spirometry for the 3-95-yr age range: the global lung function 2012 equations. Eur Respir J 2012; 40: 1324-1343.

3 Stanojevic S, Graham BL, Cooper BG, et al. Official ERS technical standards: Global Lung Function Initiative reference values for the carbon monoxide transfer factor for Caucasians. Eur Respir J 2017; 50: 1700010.

4 Cooper BG, Stocks J, Hall GL, et al. The Global Lung Function Initiative (GLI) Network: bringing the world's respiratory reference values together. Breathe (Sheff) 2017; 13: e56-e64.

5 Raghu G, Collard HR, Egan JJ, et al. An official ATS/ERS/JRS/ALAT statement: idiopathic pulmonary fibrosis: evidence-based guidelines for diagnosis and management. Am J Respir Crit Care Med 2011; 183: 788-824.

6 Plantier L, Cazes A, Dinh-Xuan A-T, et al. Physiology of the lung in idiopathic pulmonary fibrosis. Eur Respir Rev 2018; 27: 170062.

7 Kaminsky DA, Whitman T, Callas PW. DLCO versus DLCO/VA as predictors of pulmonary gas exchange. Respir Med 2007; 101: 989-994.

8 Raghu G. Idiopathic pulmonary fibrosis: lessons from clinical trials over the past 25 years. Eur Respir J 2017; 50: 1701209.

9 Raghu G, Richeldi L. Current approaches to the management of idiopathic pulmonary fibrosis. Respir Med 2017; 129: 24-30.

10 Cotes JE, Chinn DJ, Quanjer PH, et al. Standardization of the measurement of transfer factor (diffusing capacity). Report Working Party Standardization of Lung Function Tests, European Community for Steel and Coal. Official Statement of the European Respiratory Society. Eur Respir J 1993; 6: Suppl. 16, 41-52.

11 Crapo RO, Morris AH. Standardized single breath normal values for carbon monoxide diffusing capacity. Am Rev Respir Dis 1981; 123: 185-189.

12 Miller A, Thornton JC, Warshaw R, et al. Single breath diffusing capacity in a representative sample of the population of Michigan, a large industrial state. Predicted values, lower limits of normal, and frequencies of abnormality by smoking history. Am Rev Respir Dis 1983; 127: 270-277.

13 Neas LM, Schwartz J. The determinants of pulmonary diffusing capacity in a national sample of U.S. adults. Am J Respir Crit Care Med 1996; 153: 656-664.

14 Pellegrino R, Viegi G, Brusasco V, et al. Interpretative strategies for lung function tests. Eur Respir J 2005; 26: 948-968. 